University of Wollongong

Research Online

Australian Institute for Innovative Materials -

Papers

Australian Institute for Innovative Materials

$1-1-2020$

High-performance room-temperature sodium-sulfur battery enabled by electrocatalytic sodium polysulfides full conversion

Nana Wang

University of Wollongong, nw415@uowmail.edu.au

Yunxiao Wang

University of Wollongong, yunxiao@uow.edu.au

Zhongchao Bai

zbai@uow.edu.au

Zhiwei Fang

Xiao Zhang

See next page for additional authors

Follow this and additional works at: https://ro.uow.edu.au/aiimpapers

Part of the Engineering Commons, and the Physical Sciences and Mathematics Commons

Research Online is the open access institutional repository for the University of Wollongong. For further information contact the UOW Library: research-pubs@uow.edu.au 


\title{
High-performance room-temperature sodium-sulfur battery enabled by electrocatalytic sodium polysulfides full conversion
}

\author{
Abstract \\ (C) 2020 The Royal Society of Chemistry. Room-temperature sodium-sulfur (RT-Na-S) batteries are highly \\ desirable for grid-scale stationary energy storage due to their low cost; however, short cycling stability \\ caused by the incomplete conversion of sodium polysulfides is a major issue for their application. Herein, \\ we introduce an effective sulfiphilic host, gold nanodots decorated on hierarchical N-doped carbon \\ microspheres ( $\mathrm{CN} / \mathrm{Au} / \mathrm{S})$, to achieve completely reversible conversion reactions in the $\mathrm{S}$ cathode by \\ electrocatalyzing the low-kinetics conversion of Na2S4 into NaS2 (discharge process) or S (charge \\ process). Besides, gold nanodots and $\mathrm{N}$-doped carbon can increase the conductivity of the $\mathrm{S}$ cathode and \\ provide strong polar-polar adsorption of sodium polysulfides to alleviate the shuttling effects. When \\ serving as the cathode, the $\mathrm{CN} / \mathrm{Au} / \mathrm{S}$ composite can realize enhanced sulfur utilization, excellent cycling \\ stability, and outstanding rate capability. This work deepens our understanding of the catalytic effect of \\ gold atoms on sulfur molecules, opening a new avenue for cathode design and development of advanced \\ RT-Na-S batteries.

\section{Disciplines} \\ Engineering | Physical Sciences and Mathematics

\section{Publication Details} \\ Wang, N., Wang, Y., Bai, Z., Fang, Z., Zhang, X., Xu, Z., Ding, Y., Xu, X., Du, Y., Dou, S. \& Yu, G. (2020). High- \\ performance room-temperature sodium-sulfur battery enabled by electrocatalytic sodium polysulfides full \\ conversion. Energy and Environmental Science, 13 (2), 562-570.

\section{Authors} \\ Nana Wang, Yunxiao Wang, Zhongchao Bai, Zhiwei Fang, Xiao Zhang, Zhongfei Xu, Yu Ding, Xun Xu, Yi Du, \\ Shi Xue Dou, and Guihua Yu
}




\section{High-performance room-temperature sodium-sulfur battery enabled by electrocatalytic sodium polysulfides full conversion}

Received 00th January 20xx, Accepted 00th January 20xx

DOI: $10.1039 / x 0 x x 00000 x$

\author{
Nana Wang, ${ }^{a b}+$ Yunxiao Wang, ${ }^{a}+$ Zhongchao Bai, ${ }^{{ }_{+}}+$Zhiwei Fang, ${ }^{b}$ Xiao Zhang, ${ }^{b}$ Zhongfei Xu, ${ }^{a}{ }$ Yu

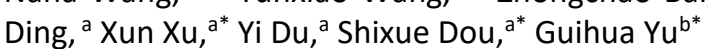

\begin{abstract}
Room-temperature sodium-sulfur (RT-Na-S) batteries are highly desirable for grid-scale stationary energy storage due to its low cost; however, short cycling stability caused by the incomplete conversion of sodium polysulfides is a major issue for their applications. Herein, we introduce an effective sulfiphilic host, gold nanodots decorated on hierarchical $\mathrm{N}$-doped carbon microspheres $(\mathrm{CN} / \mathrm{Au} / \mathrm{S})$, to achieve completely reversible conversion reactions in the $\mathrm{S}$ cathode through electrocatalyzing low-kinetics conversion $\mathrm{Na}_{2} \mathrm{~S}_{4}$ into $\mathrm{NaS}_{2}$ (discharge process) or $\mathrm{S}$ (charge process). Besides, gold nanodots and $\mathrm{N}$-doped carbon can increase the conductivity of the $\mathrm{S}$ cathode and provide strong polar-polar adsorption of sodium polysulfides to alleviate the shuttling effects. When serving as cathode, the CN/Au/S can realize enhanced sulfur utilization, excellent cycling stability, and outstanding rate capability. This work deepens our understanding of the catalytic effect of gold atoms on sulfur molecules, opening a new avenue for cathode design and the development of advanced RT-Na-S batteries.
\end{abstract}

\section{Broader context}

Developing large-scale energy storage systems is the top priority to integrate renewable but intermittent energy sources, such as solar and wind, into the electric grid. Room-temperature sodium-sulfur battery technology (RT-Na-S) is emerging as a very promising candidate with high energy density, low-cost, and large-scale stationary storage potential. The successful application of RT-Na-S will pave the way for shifting fossil fuels towards renewable energy system to power our economy in the long run. The low electroactivity of $\mathrm{S}$ and $\mathrm{Na}$, however, results in incomplete reaction during charge/discharge process, leading to very low capacity. In our work, the introduction of gold nanocluster as an electrocatalyst can facilitate a completely reversible reaction between $\mathrm{S}$ and $\mathrm{Na}$, demonstrating record high capacity and high rate performance. This work presents an appealing and competitive RT-Na-S battery with great potential for stationary storage applications.

\section{Introduction}

Efficient energy storage and conversion is essential to realize a sustainable society because it is the bridge between the grid and the intermittently available renewable energy sources ${ }^{1,2}$. Among the various state-of-the-art energy storage devices, the roomtemperature sodium-sulfur battery (RT-Na-S, Scheme 1a) has attracted particular attention due to its advantages of resource abundance (both sulfur and the sodium), nontoxicity, low cost, and high energy density ${ }^{1-3}$. Unfortunately, the practical application of RT$\mathrm{Na}-\mathrm{S}$ has been retarded by several primary challenges, such as the low conductivity of sulfur and sodium sulfides, the huge volume variation of sulfur, and the low electroactivity of $\mathrm{S}$ and $\mathrm{Na}$, as well as the dissolution of sodium polysulfide (NaPS) intermediates during cycling ${ }^{3,4}$. The sluggish reactivity of $\mathrm{S}$ with $\mathrm{Na}$ causes an incomplete reduction of $\mathrm{NaPS}$ towards $\mathrm{Na}_{2} \mathrm{~S}$ (in discharge process) or $\mathrm{S}$ (in charge process), resulting in low sulfur utilization and reversible capacity ${ }^{5-8}$. The dissolution of polysulfide intermediates incurs shuttling effects and serious self-discharge and exacerbates capacity decay.

\footnotetext{
a. Institute for Superconducting and Electronic Materials, University of Wollongong, Innovation Campus, Squires Way, Wollongong, New South Wales 2500, Australia b. Materials Science and Engineering Program and Department of Mechanical

Engineering, The University of Texas at Austin, Austin, Texas 78712, United States + These authors contributed equally to this work.

Electronic Supplementary Information (ESI) available: [details of any supplementary information available should be included here]. See DOI: 10.1039/x0xx00000x
}

Therefore, the priority is to realize the confinement and conversion of the polysulfides in the cathode for a better RT-Na-S.

Recent research has gained progress in trapping NaPSs through physical and chemical anchoring strategies, based on the lessons from Li-S batteries ${ }^{9-14}$. Carbon nanostructures, the most studied sulfur host, have been scientifically devised with good electrical conductivity and appropriate pores to host sulfur particles and physically restrict NaPSs. Their nonpolar feature cannot produce effective interactions with the polar sodium polysulfides, however, and the corresponding $\mathrm{S}$ cathodes suffer from gradual capacity decay and poor rate capability. Recently developed polar hosts, such as metal dichalcogenides and metal nanoparticles, have demonstrated effective trapping of NaPSs through polar-polar interactions or strong chemical binding. Although the performance of RT-Na-S batteries was enhanced to some extent, these results are still far from expectation due to the sluggish reaction kinetics of $\mathrm{Na}_{2} \mathrm{~S}$ and $\mathrm{NaPSs}^{15}$. For example, Wang et al. discovered that the reversible reactions of RT-Na-S can only occur between $\mathrm{S}_{8}$ and $\mathrm{Na}_{2} \mathrm{~S}_{4}$, based on in situ synchrotron X-ray diffraction (XRD), corresponding to a capacity of $418 \mathrm{mAh} \mathrm{g}^{-1}$. This is only a quarter of the theoretical capacity of a $\mathrm{Na}-\mathrm{S}$ battery when the Na-storage reaction is fully complete with $\mathrm{Na}_{2} \mathrm{~S}$ as the final discharge product $\left(1672 \mathrm{mAh} \mathrm{g}^{-1}\right)^{13}$. Furthermore, the sluggish kinetics of this process not only causes an accumulation of soluble NaPSs in the cathode, which inevitably exacerbates the shuttle effect, but also results in the formation of large $\mathrm{Na}_{2} \mathrm{~S}$ particles, which are hard to recycle in the following 
discharge-charge processes due to their harsh activation energy and poor electrical conductivity ${ }^{3,16}$. Therefore, advanced strategies to improve the kinetics of NaPS conversion at the cathode need to be developed.

Various catalysts, such as platinum (Pt), cobalt (Co), and metal oxides/sulfides/nitrides, have been utilized to enhance the conversion rates of soluble lithium polysulfides to insoluble $S$ (in the charge process) or $\mathrm{Li}_{2} \mathrm{~S}$ (in the discharge process) ${ }^{17-23}$. Significantly, Arava et al. found that the use of Pt or Au as a catalyst could greatly enhance the reaction kinetics of the Li-S battery, because the strong non-chemisorbed gold-sulfur bond $(2.5 \mathrm{eV})$ can effectively immobilize polysulfides without decreasing their reuse in the following cycle ${ }^{17,24}$. Furthermore, gold nanocatalysts (with particle diameters below $10 \mathrm{~nm}$ ) have been demonstrated to be astonishingly active towards electrochemical energy storage reactions, with examples such as Au-doped $\mathrm{MnO}_{2}$ and nanoporous gold/ $/ \mathrm{MnO}_{2}$ films delivering significantly enhanced supercapacitor performance ${ }^{25,26}$. This concept has been introduced into the RT-Na-S system to solve the same problems as in Li-S batteries ${ }^{15,16}$. Nevertheless, electrochemical reversibility between sodium disulfide and sulfur is not achieved ${ }^{15}$. Nor have high rate RT-Na-S batteries been realized. Encouraged by the good conductivity and catalytic activity of gold atoms, in particular, since gold is more stable in electrochemical reactions than other transition metals, the introduction of gold into the RT-Na-S system is expected to effectively solve its sluggish kinetics problems.

Here we propose a new class of electrocatalytic gold nanodots as a catalyst for advanced RT-Na-S batteries. Based on in situ X-ray diffraction (XRD) patterns, cyclic voltammetry (CV), and theoretical calculations, we find that gold nanocrystals can not only effectively trap the NaPSs via the strong gold-sulfur binding to alleviate the shuttle effect, but also greatly boost the conversion rates of NaPSs to improve the utilization of sulfur. In particular, gold nanodotdecorated carbon hosts could catalyze intermediate $\mathrm{Na}_{2} \mathrm{~S}_{4}$ so that it is completely transformed into $\mathrm{Na}_{2} \mathrm{~S}$ in the discharge process and into $S$ in the charge process, facilitating a completely reversible reaction between $\mathrm{S}$ and $\mathrm{Na}_{2} \mathrm{~S}$. Consequently, the $\mathrm{CN} / \mathrm{Au} / \mathrm{S}$ cathode delivered excellent electrochemical performance, including high specific capacity (701 mAh g-1 after the $110^{\text {th }}$ cycle at $\left.0.1 \mathrm{~A} \mathrm{~g}^{-1}\right)$, long cycling stability, and high rate capability (369 $\mathrm{mAh} \mathrm{g}^{-1}$ at $10 \mathrm{~A} \mathrm{~g}^{-1}$ after 2000 cycles), demonstrating great potential for application in large-scale energy storage devices.

\section{Results and discussion}

\section{Synthesis and Structure of the $\mathrm{CN} / \mathrm{Au} / \mathrm{S}$ Composite.}

The formation procedures for $\mathrm{CN} / \mathrm{Au} / \mathrm{S}$ are schematically illustrated in Scheme 1b. First, uniform $\mathrm{MnCO}_{3}$ microspheres (see Fig. S1) were heated in $\mathrm{Ar}$ atmosphere to decompose into porous $\mathrm{Mn}_{2} \mathrm{O}_{3}$ microspheres, in which $\mathrm{Mn}_{2} \mathrm{O}_{3}$ nanoparticles cross-linked to form the porous structure (see Fig. S2). Then resorcinol-formaldehyde resin and melamine as the carbon and nitrogen source, respectively, were used to coat a carbon layer on the surfaces of the cross-linked $\mathrm{Mn}_{2} \mathrm{O}_{3}$ nanoparticles as well as the whole microspheres. During carbonization in $\mathrm{Ar}$ atmosphere, the coated $\mathrm{Mn}_{2} \mathrm{O}_{3}$ composite can transform into MnO@N-doped carbon microspheres (denoted as

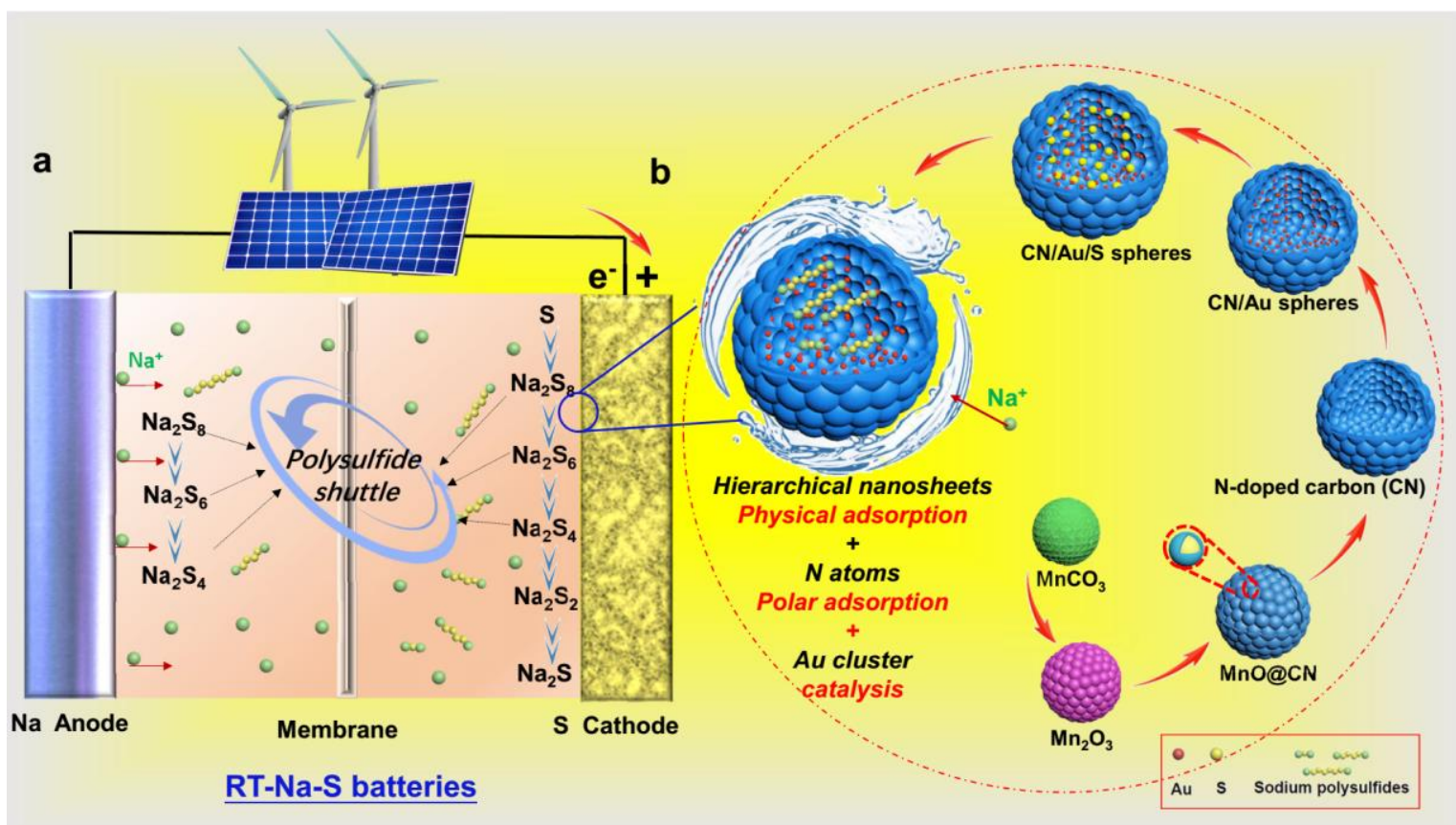

Scheme 1. (a) Schematic of working principle of a sulfur cathode for RT-Na-S batteries, and RT-Na-S batteries are regarded as an important choice to modulating renewable resources (solar, wind, etc.) for large-scale applications. (b) Synthesis protocol for the $\mathrm{CN} / \mathrm{Au} / \mathrm{S}$ microspheres used in Na-S batteries. 

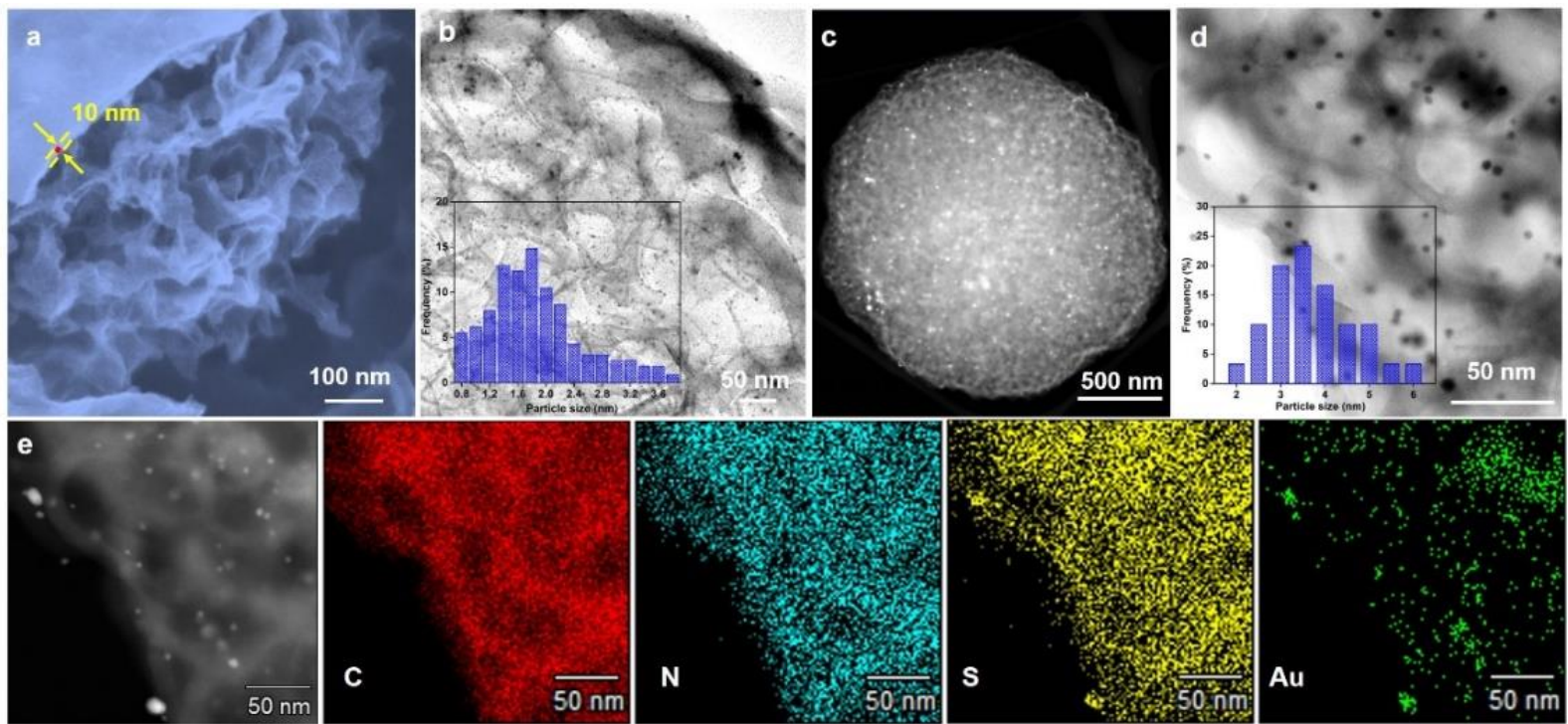

Fig. 1. Morphology characterization of $C N, C N / A u$, and $C N / A u / S$ samples. (a) SEM image of one broken $C N$ microsphere. (b) STEM image of a CN/Au sample with particle size distribution of gold nanodots (inset). (c) Dark-field STEM image, (d) STEM image of CN/Au/S sample with particle size distribution of gold nanodots (inset). (e) Dark-field TEM image and corresponding elemental mapping images of $\mathrm{CN} / \mathrm{Au} / \mathrm{S}$ sample.

MnO@CN) (see Fig. S3). Hierarchical porous microspheres crosslinked by ultrathin $\mathrm{N}$-doped carbon nanosheets (denoted as $\mathrm{CN}$, see Fig. S4) were obtained by a facile $\mathrm{HCl}$ etching process. Afterwards, gold nanodots were loaded into the interior crosslinking carbon nanosheets of the $\mathrm{CN}$, which is denoted as $\mathrm{CN} / \mathrm{Au}$. Followed by $\mathrm{S}$ encapsulation process, a $\mathrm{CN} / \mathrm{Au} / \mathrm{S}$ composite is prepared and expected to be a multifunctional $\mathrm{S}$ cathode in $\mathrm{RT}-\mathrm{Na}-\mathrm{S}$ batteries. The $\mathrm{CN}$ microspheres with interconnected interior 2D nanosheets can serve as micro reactors of $\mathrm{S}$ during charge/discharge processes, which can not only supply channels for electrolyte penetration and ion transport, but also can serve as reservoirs to alleviate dissolution of polysulfide intermediates via both physical and polar adsorption. More importantly, combined with increasing conductivity of $S$ cathode and forming non-chemisorbed gold-sulfur bond. the ultrafine gold nanodots could provide effectively catalysis towards the conversion of sodium polysulfides, which will further boost the electrochemical performance of RT-Na-S batteries.

The morphological evolution of $\mathrm{CN}, \mathrm{CN} / \mathrm{Au}$ and $\mathrm{CN} / \mathrm{Au} / \mathrm{S}$ samples were shown in Fig. 1. A broken $\mathrm{CN}$ microsphere clearly displays cross-linked $\mathrm{N}$-doped carbon nanosheets inside, and the thickness of the utmost spherical layer is $~ 10 \mathrm{~nm}$ (Fig. 1a). The lowmagnification SEM images demonstrate the same morphology of $\mathrm{CN}$ and CN/Au samples, with a diameter around $2 \mu \mathrm{m}$ (see Fig. S5). Specifically, scanning transmission electron microscopy (STEM) images illustrate that Au nanodots with mean size of $1.8 \mathrm{~nm}$ are uniformly distributed on the carbon nanosheets (both external and internal) (Fig. 1b and Fig. S5c). In contrast, the size of Au nanodots in $\mathrm{CN} / \mathrm{Au} / \mathrm{S}$ increases to $2.5-5.0 \mathrm{~nm}$ after sulfur loading, which is due to the strong absorption of Au nanodots for sulfur and agglomeration of Au nanodots during the heating process, (Fig. 1c-1e). Furthermore, corresponding elemental mapping demonstrates that sulfur is more likely to be distributed along the gold atoms rather than the $\mathrm{CN}$ backbones, indicating the strong absorption between $\mathrm{Au}$ and $\mathrm{S}$.

The XRD patterns of $\mathrm{CN} / \mathrm{Au} / \mathrm{S}, \mathrm{CN} / \mathrm{Au}, \mathrm{CN}$, and $\mathrm{S}$ are shown in Fig. 2a. The narrow and sharp diffraction peaks demonstrate that pristine sulfur is in a high crystallization state, while the plain lines of $\mathrm{CN}$ and $\mathrm{CN} / \mathrm{Au}$ manifest the amorphous nature of $\mathrm{CN}$ and the ultrafine size of the Au nanodots. After encapsulating crystalline sulfur into the $\mathrm{CN}$ (sample denoted as $\mathrm{CN} / \mathrm{S}$ ) and $\mathrm{CN} / \mathrm{Au}$, the sharp diffraction peaks of bulk crystalline sulfur almost completely disappear (see Fig. S6), demonstrating that the sulfur is highly dispersed in a low-molecular monolayered state inside the pores of the carbon host, which is agreement with the thermogravimetric analysis (TGA) results ${ }^{16,27}$. As shown in Fig. $2 \mathrm{~b}$ and Fig. S7, two thirds of the sulfur has evaporated at temperatures above $270{ }^{\circ} \mathrm{C}$, which indicates that most of the sulfur is confined in the micropores or encapsulated in the hollow spaces of the carbon matrix. Such a well dispersed state would greatly improve the electrical conductivity of the sulfur cathode ${ }^{13,16}$. The sulfur content was confirmed by TGA to be $52.9 \mathrm{wt} \%$ for $\mathrm{CN} / \mathrm{S}$ and $56.5 \mathrm{wt} \%$ for $\mathrm{CN} / \mathrm{Au} / \mathrm{S}$. The slightly higher $\mathrm{S}$ ratio of $\mathrm{CN} / \mathrm{Au} / \mathrm{S}$ is likely due to the strong adsorption of ultrafine Au nanodots on $\mathrm{S}$. The $\mathrm{N}_{2}$ adsorption analysis for $\mathrm{CN} / \mathrm{Au}$ the samples demonstrate Type IV isotherms along with H3 hysteresis loops, demonstrating the mesoporous structure of carbon microspheres (Fig. 2c). The CN/Au sample possesses a high surface area (766.4 $\left.\mathrm{m}^{2} / \mathrm{g}\right)$ and pore volume $\left(0.66 \mathrm{~cm}^{3} / \mathrm{g}\right)$, calculated based on the Brunauer-Emmett-Teller (BET) method, with the pore size distribution centered around $2.8 \mathrm{~nm}$ (inset to Fig. 2c). After sulfur loading, the surface area and pore volume sharply decreased to 71.4 $\mathrm{m}^{2} / \mathrm{g}$ and $0.17 \mathrm{~cm}^{3} / \mathrm{g}$, respectively, owing to the sulfur filled into the pores of the $\mathrm{CN} / \mathrm{Au}$ microspheres ${ }^{27}$.

The chemical states of the $\mathrm{CN}, \mathrm{CN} / \mathrm{Au}$, and $\mathrm{CN} / \mathrm{Au} / \mathrm{S}$ samples were further investigated by $\mathrm{X}$-ray photoelectron spectroscopy (XPS). The $\mathrm{N}$ 1s spectrum of $\mathrm{CN} / \mathrm{Au} / \mathrm{S}$ and $\mathrm{CN}$ could be divided into two peaks at 399.4 and $400.6 \mathrm{eV}$, which are attributed to the binding energies of pyridinic and pyrrolic nitrogen (Fig. $2 \mathrm{~d}$ and Fig. S8), respectively ${ }^{28-30}$. The $C 1 \mathrm{~s}$ spectrum in Fig. $\mathrm{S} 9$ can be fitted as a sum of C-C (284.6 eV), C-N (286.2 eV), C-O (287.1 eV), and C=O (288.7 eV) bonds, which resulted from moisture in the sample as well as the native surface groups ${ }^{28-30}$. The $\mathrm{N}$ heteroatom doping could effectively enhance the interaction between the carbon host and the lithium polysulfide guests in Li-S batteries through the introduction of polarity. Hence, it is expected that $\mathrm{CN}$ hosts with the $\mathrm{N}$ heteroatom 


\section{PAPER}
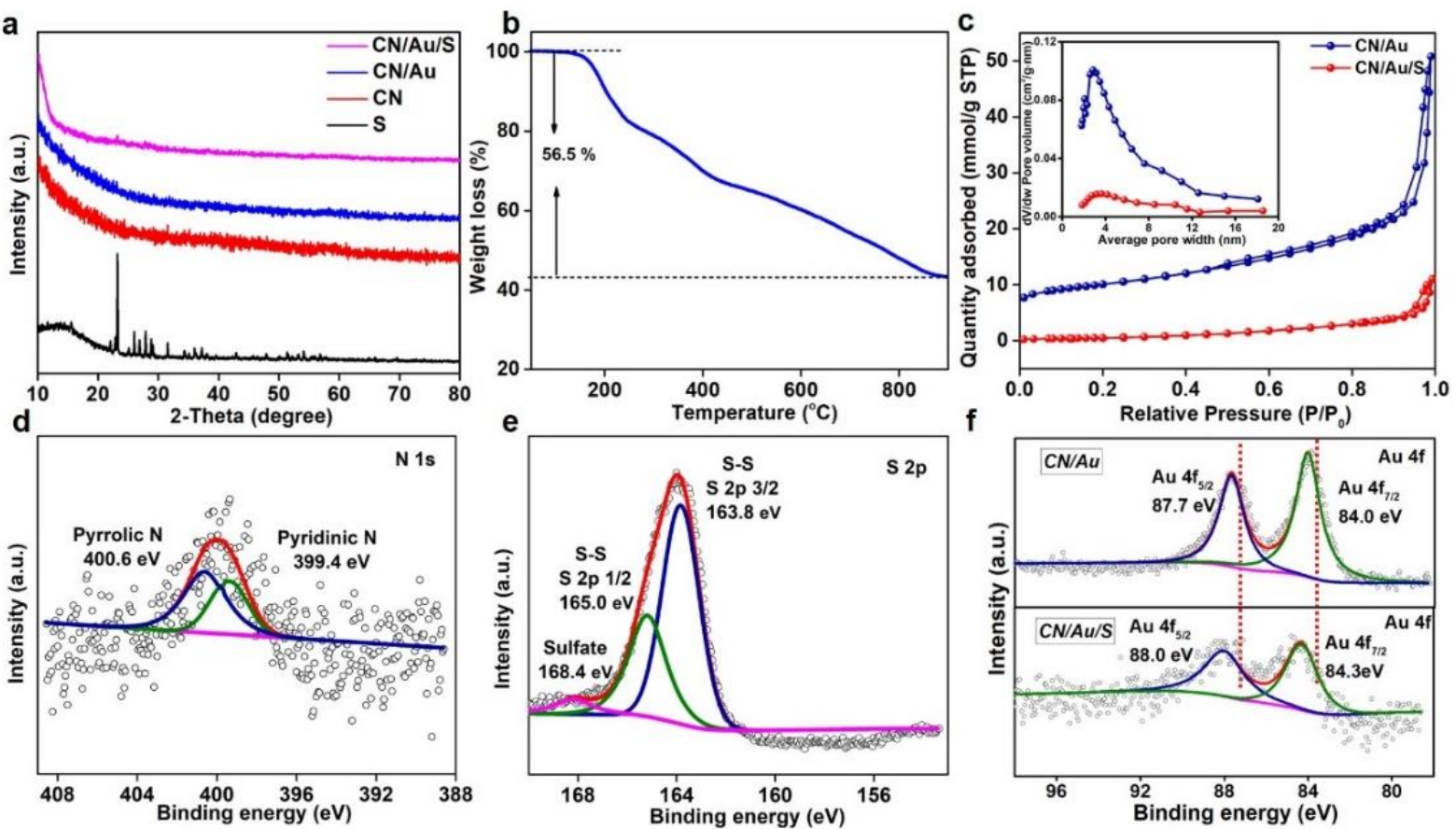

Fig. 2. Structural characterization of the $C N / A u / S$ sample. (a) XRD patterns of $C N / A u / S, C N / A u, C N$, and $S$ samples. (b) $T G A$ curve of $C N / A u / S$ sample. (c) $N_{2}$ absorption/desorption isotherms and pore size distribution (inset) for CN/Au and CN/Au/S samples. High-resolution XPS spectra of (d) N 1s and (e) $S 2 p$ for $\mathrm{CN} / \mathrm{Au} / \mathrm{S}$ sample, and (f) $\mathrm{Au} 4 \mathrm{f}$ for the $\mathrm{CN} / \mathrm{Au}$ and $\mathrm{CN} / \mathrm{Au} / \mathrm{S}$ sample.

doping could also facilitate a better anchoring effect on NaPSs in Na$S$ batteries ${ }^{31}$. After loading with Au and sulfur, the survey spectra of the $\mathrm{CN} / \mathrm{Au} / \mathrm{S}$ and $\mathrm{CN} / \mathrm{Au}$ samples indicate the presence of $\mathrm{Au}$ and $\mathrm{S}$ elements without any changes in the $\mathrm{C}$ or $\mathrm{N}$ spectrum (see Fig. S10), because no chemical reaction takes place between the carbon matrix and the sulfur, indicating that there is mainly physical absorption between $\mathrm{CN}$ hosts and sulfur guests. Fig. 2e displays two typical peaks at 163.8 and $165.0 \mathrm{eV}$, corresponding to signals of $\mathrm{S} 2 \mathrm{p}_{3 / 2}$ and $\mathrm{S} 2 \mathrm{p}_{1 / 2}$, owing to the spin-orbit split coupling. In addition, the peak located at $168.4 \mathrm{eV}$ is assigned to sulfate with highly oxidized sulfur species $^{30}$. For the $\mathrm{CN} / \mathrm{Au}$ sample, two typical peaks at 84.0 and 87.7 eV generated from $A u 4 f_{7 / 2}$ and $A u 4 f_{5 / 2}$, respectively, are observed in Fig. $2 \mathrm{f}$, demonstrating that chloroauric acid is completely reduced to $\mathrm{Au}^{(0) 29}$. As for the $\mathrm{Au} 4 \mathrm{f}$ spectrum in the $\mathrm{CN} / \mathrm{Au} / \mathrm{S}$ sample, the peaks with higher binding energy compared to the CN/Au sample indicate the strong adsorption between Au nanodots and sulfur guests, which is predicted to achieve strong interfacial interaction to trap sodium polysulfides during cycling, resulting in long cycling stability.

\section{Electrochemical mechanism.}

To understand the $\mathrm{Na}-\mathrm{S}$ chemistry of $\mathrm{CN} / \mathrm{Au} / \mathrm{S}$, in situ synchrotron $\operatorname{XRD}(\lambda=0.6888 \AA$ ) (SXRD) was performed to track the changes in the produced species during discharge/charge processes. As shown in Fig. 3, relatively strong characteristic peaks of sulfur are detected in the fresh cell because of the high resolution of SXRD. In the initial discharge state (OCP (open-circuit potential) $-1.8 \mathrm{~V}$ ), the peaks of sulfur gradually become weak, while the peaks of polysulfides $\left(\mathrm{Na}_{2} \mathrm{~S}_{5}\right.$, JCPDS Card No. 44-0823) evolve and are growing in intensity (2.0-1.8 $\mathrm{V})$. With the depth of discharge increasing (from 1.8 to $1.0 \mathrm{~V}$ ), the peaks of $\mathrm{Na}_{2} \mathrm{~S}_{5}$ gradually disappear; meanwhile, the peaks of $\mathrm{Na}_{2} \mathrm{~S}_{4}$ (JCPDS Card No. 25-1112) start to show increasingly high intensity. When the cell is further discharged $(0.8 \mathrm{~V})$, only $\mathrm{Na}_{2} \mathrm{~S}$ is detected without any other sulfur species, indicating that $\mathrm{Na}_{2} \mathrm{~S}_{4}$ has been totally converted into $\mathrm{Na}_{2} \mathrm{~S}$ (JCPDS Card No. 47-1698). This result is very different from that found in previous work (with only carbon used as the host material), where $\mathrm{Na}_{2} \mathrm{~S}_{4}$ and $\mathrm{Na}_{2} \mathrm{~S}$ were both observed in SXRD when the cell was discharged to $0.8 \mathrm{~V}$, which is also consistent with our ex situ XRD investigation (see Fig. S11). When the $\mathrm{CN} / \mathrm{S}$ sample was discharged to $0.8 \mathrm{~V}, \mathrm{Na}_{2} \mathrm{~S}_{4}$ and $\mathrm{Na}_{2} \mathrm{~S}$ were both detected. These results revealed that gold nanodots could effectively catalyze soluble $\mathrm{Na}_{2} \mathrm{~S}_{4}$ into insoluble $\mathrm{Na}_{2} \mathrm{~S}$ in the discharge process. 
a

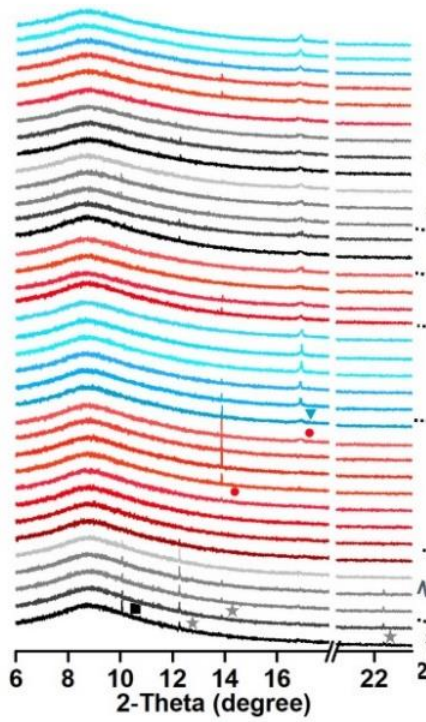

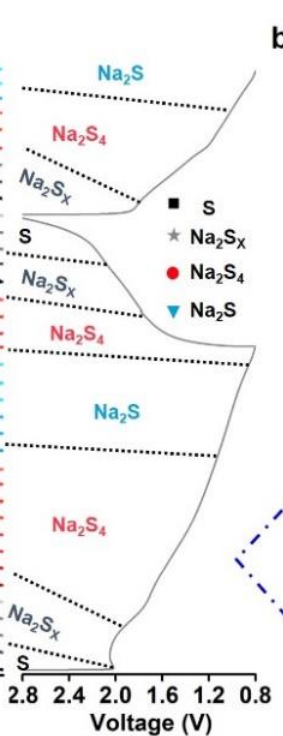
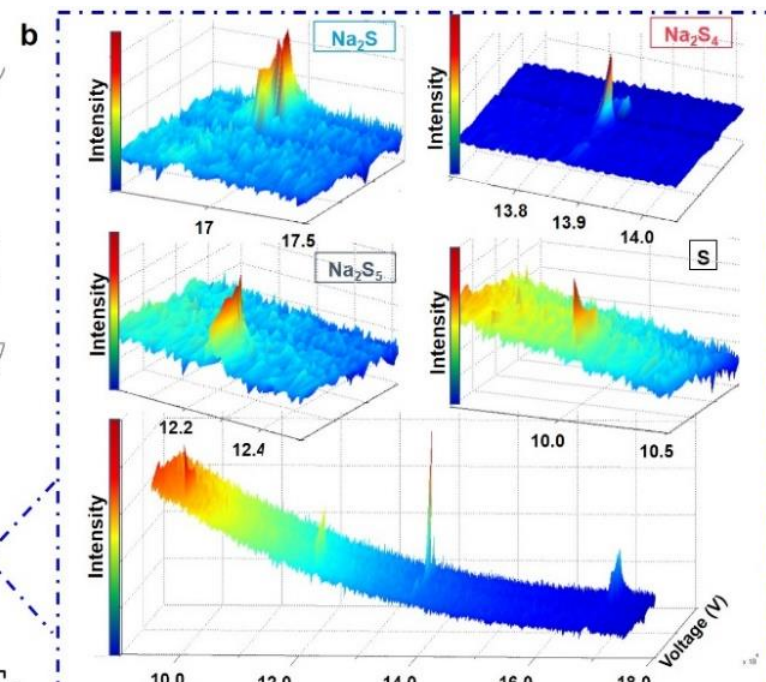

13.8

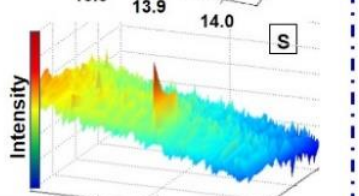

14.0

16.0
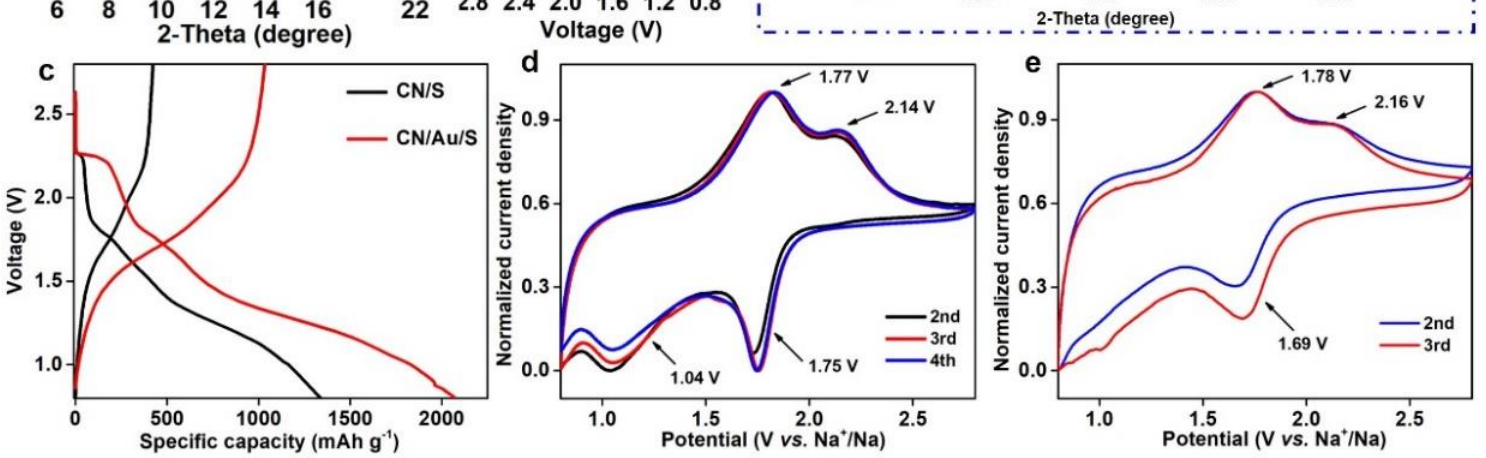

Fig. 3. Mechanism of CN/Au/S activity in RT-Na-S batteries. (a) In situ synchrotron XRD patterns of charged and discharged CN/Au/S sample in RT-Na-S batteries. (b) Contour plot of XRD patterns with selected theta for intermediate products. (c) Charge/discharge profiles of CN/Au/S and CN/S samples. CV curves for (d) $\mathrm{CN} / \mathrm{Au} / \mathrm{S}$ and (e) CN/S samples.

In the subsequent charge process, $\mathrm{Na}_{2} \mathrm{~S}_{4}$ is observed in both in situ synchrotron XRD and ex situ XRD investigations (Fig. 3a, 3b and Fig. S11). More surprisingly, unlike single-atom cobalt catalyst, gold can catalyze $\mathrm{Na}_{2} \mathrm{~S}_{4}$ to totally turn into $\mathrm{S}$ in the charge process (2.4-2.8 V). Without the Au catalysis, some irreversible $\mathrm{Na}_{2} \mathrm{~S}_{4}$ can be detected in $\mathrm{CN} / \mathrm{S}$ (see Fig. S11b). As shown in Fig. 3c, the different electrochemical reactions between $\mathrm{CN} / \mathrm{Au} / \mathrm{S}$ and $\mathrm{CN} / \mathrm{S}$ can also be identified in the charge-discharge process. Although both samples displayed a plateau at about $2.25 \mathrm{~V}$ (in the discharge), the intensity for $\mathrm{CN} / \mathrm{Au} / \mathrm{S}$ is much stronger than that for $\mathrm{CN} / \mathrm{S}$, indicating that $\mathrm{S}$ is more fully converted into polysulfide in $\mathrm{CN} / \mathrm{Au} / \mathrm{S}$ than in $\mathrm{CN} / \mathrm{S}$, which reflected by the XRD patterns, as the peak intensity of NaPSs for $\mathrm{CN} / \mathrm{Au} / \mathrm{S}$ is stronger than for $\mathrm{CN} / \mathrm{S}$ (see Fig. S11). The slopes between 2.25-1.8 $\mathrm{V}$ and 1.8-1.3 $\mathrm{V}$ are almost identical in the two samples, resulting in similar XRD patterns in this region. The biggest difference occurs at 1.3-0.8 V, where the slope of $\mathrm{CN} / \mathrm{Au} / \mathrm{S}$ is much longer than that of $\mathrm{CN} / \mathrm{S}$, corresponding to complete $\mathrm{Na}_{2} \mathrm{~S}_{4}$ conversion to $\mathrm{Na}_{2} \mathrm{~S}$ in $\mathrm{CN} / \mathrm{Au} / \mathrm{S}$ and not in $\mathrm{CN} / \mathrm{S}$. The first discharge capacity of $\mathrm{CN} / \mathrm{Au} / \mathrm{S}$ is $2050 \mathrm{mAh} \mathrm{g}^{-1}$, which is almost twice that of CN/S (1325 $\left.\mathrm{mAh} \mathrm{g}^{-1}\right)$.
These reaction discrepancies are also reflected in the CV curves. As shown in Fig. S12, the first cathodic peak attributed to the reduction of solid $\mathrm{S}$ to soluble long-chain polysulfides was found at $1.62 \mathrm{~V}$ for $\mathrm{CN} / \mathrm{Au} / \mathrm{S}$ and $1.6 \mathrm{~V}$ for $\mathrm{CN} / \mathrm{S}$, and the peak intensity of $\mathrm{CN} / \mathrm{Au} / \mathrm{S}$ is little stronger than that of $\mathrm{CN} / \mathrm{S}$. The peak corresponding to the sodiation of long-chain polysulfides to $\mathrm{Na}_{2} \mathrm{~S}_{4}$ and then to $\mathrm{Na}_{2} \mathrm{~S}$ is centered at $1.01 \mathrm{~V}$ for $\mathrm{CN} / \mathrm{Au} / \mathrm{S}$ and $0.9 \mathrm{~V}$ for $\mathrm{CN} / \mathrm{S}$. This peak of $\mathrm{CN} / \mathrm{Au} / \mathrm{S}$ is reversible and shifts to $1.04 \mathrm{~V}$ in the following cycles (Fig. $3 d$ ). That of $\mathrm{CN} / \mathrm{S}$ is not detected in following cycles, however, indicating that this reaction is not fully reversible in CN/S (Fig. 3e). In the charge process, two anodic peaks are observed in both samples. The first one is ascribed to the formation of $\mathrm{Na}_{2} \mathrm{~S}_{4}$ and polysulfides, and the second one corresponds to oxidation of polysulfides to $S$. The second peak of $\mathrm{CN} / \mathrm{Au} / \mathrm{S}$ is much stronger than that of $\mathrm{CN} / \mathrm{S}$, which is in good agreement with the in situ SXRD and ex situ XRD data, where $\mathrm{Na}_{2} \mathrm{~S}_{4}$ is completely changed into $\mathrm{S}$ by the Au catalyst in CN/Au/S. 

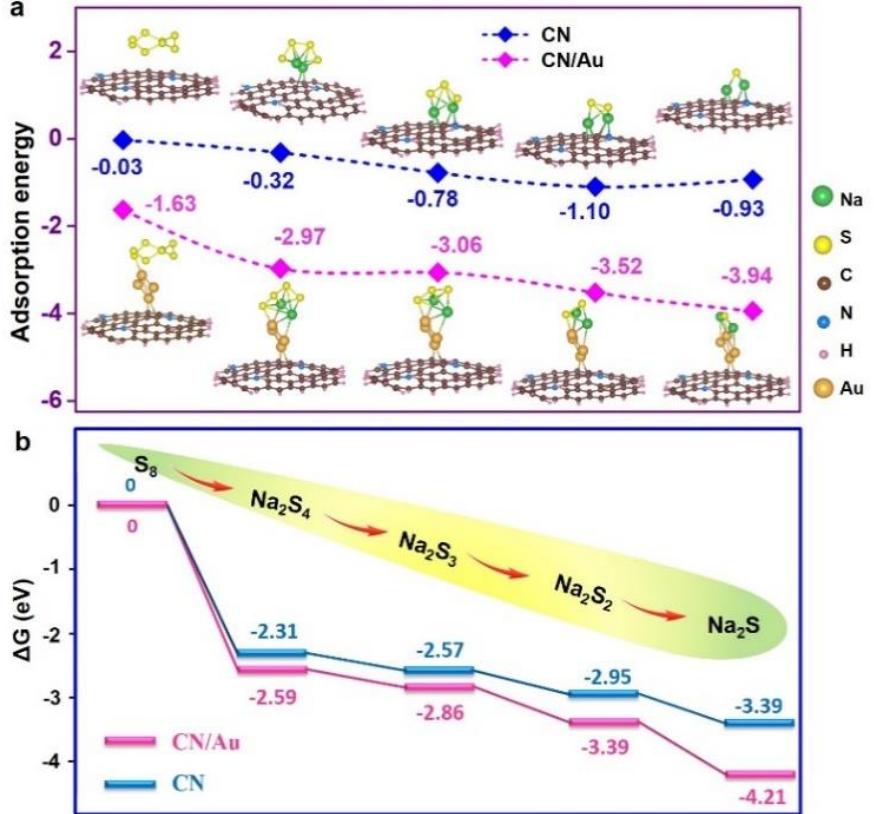

Fig. 4. Energy profiles for sodium polysulphides on $\mathrm{CN}$ and $\mathrm{CN} / \mathrm{Au}$ samples. (a) The adsorption energies and (b) the Gibbs free energies of NaPSs bound on the nitrogen doped carbon surface and Au decorated nitrogen doped carbon.

\section{Theoretical analysis.}

To gain further insight on the electrochemical catalytic performance of $\mathrm{Au}$ in $\mathrm{Na}-\mathrm{S}$ batteries, a theoretical investigation based on density functional theory (DFT) calculations was conducted. First, the adsorption energies of $\mathrm{NaPSs}\left(\mathrm{Na}_{2} \mathrm{~S}_{4}, \mathrm{Na}_{2} \mathrm{~S}_{3}, \mathrm{Na}_{2} \mathrm{~S}_{2}\right.$, and $\left.\mathrm{Na}_{2} \mathrm{~S}\right)$ on the nitrogen doped carbon surface and on Au decorated nitrogen doped carbon were investigated by DFT calculations (Fig. 4). The nanosheets in the $\mathrm{CN}$ sample are very thin and can be considered as assembled from several layers of graphene, and thus, single-layer graphene is applied in modeling the carbon substrate to compute the adsorption of NaPS molecules. We calculate their binding energy $\left(E_{\text {bind }}\right)$ based on following relationships:

$E_{\text {bind }}=E_{\text {sub+molecule }}-E_{\text {sub }}-E_{\text {molecule }}$

where $E_{\text {sub-molecule }}$ is the total energy of the substrate with the molecule adsorbed, and $E_{\text {sub }}$ and $E_{\text {molecule }}$ are the total energies of the substrate and the isolated molecule, respectively. In general, negative binding energy demonstrates a positive adsorption capability, and the strength of the adsorption capability enhances as it becomes more negative. The calculated binding energies of $\mathrm{S}_{8}$, $\mathrm{Na}_{2} \mathrm{~S}_{4}, \mathrm{Na}_{2} \mathrm{~S}_{3}, \mathrm{Na}_{2} \mathrm{~S}_{2}$ and $\mathrm{Na}_{2} \mathrm{~S}$ are $-0.03,-0.32,-0.78,-1.10$ and -0.93 $\mathrm{eV}$, respectively, for nitrogen doped carbon (Fig. 4a). After loaded with Au nanodots, the adsorption capability of the substrate greatly improves. As shown in Fig. $4 \mathrm{a}$, the binding energies of $\mathrm{S}_{8}, \mathrm{Na}_{2} \mathrm{~S}_{4}$, $\mathrm{Na}_{2} \mathrm{~S}_{3}, \mathrm{Na}_{2} \mathrm{~S}_{2}$ and $\mathrm{Na}_{2} \mathrm{~S}$ are changed to $-1.63,-2.97,-3.06,-3.52$, and $-3.94 \mathrm{eV}$, respectively, on the $\mathrm{Au}$ loaded carbon. This result demonstrates that the Au nanodots could remarkably strength the interaction between the NaPSs and the carbon host, which is favorable for the activity of the sulfur and effectively prevents shuttling of polysulfides.
Next, the $\mathrm{S}$ reaction pathways of both $\mathrm{CN} / \mathrm{S}$ and $\mathrm{CN} / \mathrm{Au} / \mathrm{S}$ cathodes were studied. The overall reaction according to the reversible production of $\mathrm{Na}_{2} \mathrm{~S}$ from $\mathrm{S}_{8}$ and $\mathrm{Na}$ was considered. In the discharge process, the first step is the reduction of $\mathrm{S}_{8}$ to form $\mathrm{Na}_{2} \mathrm{~S}_{4}$ by $\mathrm{Na}^{+}$, following which, $\mathrm{Na}_{2} \mathrm{~S}_{4}$ experiences further reduction and, in turn, the formation of three intermediate $\mathrm{NaPSs}$, that is, $\mathrm{Na}_{2} \mathrm{~S}_{4}$, $\mathrm{Na}_{2} \mathrm{~S}_{3}$, and $\mathrm{Na}_{2} \mathrm{~S}_{2}$, resulting in the formation of $\mathrm{Na}_{2} \mathrm{~S}$ as the final product. The Gibbs free energies of the intermediates were calculated based on the above reactions on both $\mathrm{CN}$ and $\mathrm{CN} / \mathrm{Au}$ supports, and the results displayed in Fig. 4b. The downhill path of the free energy from $\mathrm{S}_{8}$ to $\mathrm{Na}_{2} \mathrm{~S}$ means spontaneous exothermic conversion, and all the conversions are spontaneous. This is more energetically favorable for $\mathrm{CN} / \mathrm{Au}$ than for $\mathrm{CN}$ because of its lower Gibbs free energy values. Catalyzing the reduction of $\mathrm{S}_{8}$ on $\mathrm{CN} / \mathrm{Au}$ is crucial to drop the energy barrier and greatly enhance the battery performance. Therefore, these $\mathrm{Au}$ nanodots could effectively mitigate the shuttle effect by confining the polysulfides through their enhanced adsorption capability by polar-polar interactions. More importantly, Au nanodots could electrocatalyze sodium polysulfide conversion and improve the utilization of $\mathrm{S}$, resulting in high specific capacity and energy density. These factors make CN/Au/S a promising cathode for high performance RT-Na-S batteries for largescale energy storage.

\section{Electrochemical performance evaluation.}

Based on the mechanism analysis and theoretical predictions for the $\mathrm{CN} / \mathrm{Au} / \mathrm{S}$ sample in RT-Na-S batteries, the electrochemical performances of the synthesized samples were comprehensively investigated. Because of the catalytic effect of Au nanoparticles, the $\mathrm{CN} / \mathrm{Au} / \mathrm{S}$ delivers not only much higher specific capacity, but also much better rate properties than CN/S (Fig. 5 , a and b). The CN/Au/S sample delivered an initial discharge capacity of $1967 \mathrm{mAh} \mathrm{g}^{-1}$ and maintained $701 \mathrm{mAh} \mathrm{g}^{-1}$ after the $110^{\text {th }}$ cycle at $0.1 \mathrm{~A} \mathrm{~g}^{-1}$. The high first discharge capacity may come from the decomposition of theelectrolyte to form the solid electrolyte interphase (SEI) layer, as well as the side reactions between the electrolyte and the carbon host (see Fig. S13). In contrast, the $\mathrm{CN} / \mathrm{S}$ only displays a discharge capacity of $1253 \mathrm{mAh} \mathrm{g}^{-1}$ in the first cycle, and only keeps $330 \mathrm{mAh}$ g${ }^{1}$ after the $110^{\text {th }}$ cycle at $0.1 \mathrm{~A} \mathrm{~g}^{-1}$. Both samples show quick capacity fade in the initial cycles due to the loss of dissolved long-chain polysulfides, and they then attain relatively good cycling stability. The rate capability of $\mathrm{CN} / \mathrm{Au} / \mathrm{S}$ and $\mathrm{CN} / \mathrm{S}$ was assessed at various current densities from 0.05 to $20 \mathrm{~A} \mathrm{~g}^{-1}$ in the voltage window of 0.8 to $2.8 \mathrm{~V}$ and shown in Fig. 5b. At every stage of current density, $\mathrm{CN} / \mathrm{Au} / \mathrm{S}$ exhibits a higher capacity than $\mathrm{CN} / \mathrm{S}$. The $\mathrm{CN} / \mathrm{Au} / \mathrm{S}$ shows average capacities of 1010, 830, 755, 678, 599, 532, 414, 297, 230, and $181 \mathrm{mAh} \mathrm{g}^{-1}$ at corresponding current densities of $0.05,0.10 .2$, $0.5,1,2,5,10,15$, and $20 \mathrm{~A} \mathrm{~g}^{-1}$. More significantly, the capacity of $\mathrm{CN} / \mathrm{Au} / \mathrm{S}$ could revert to $934 \mathrm{mAh} \mathrm{g}^{-1}$ when the current density returned to $0.05 \mathrm{~A} \mathrm{~g}^{-1}$, demonstrating that the $\mathrm{CN} / \mathrm{Au} / \mathrm{S}$ can endure various current densities. The rate property of $\mathrm{CN} / \mathrm{Au} / \mathrm{S}$ is not only better than that of our synthesized $\mathrm{CN} / \mathrm{S}$, but also the previous reports on RT-Na-S (Fig. 5c) 9,13,32,33-35. To the best of our knowledge, such an extremely high rate performance of RT-Na-S batteries significantly exceeds those reported previously. 


\section{PAPER}
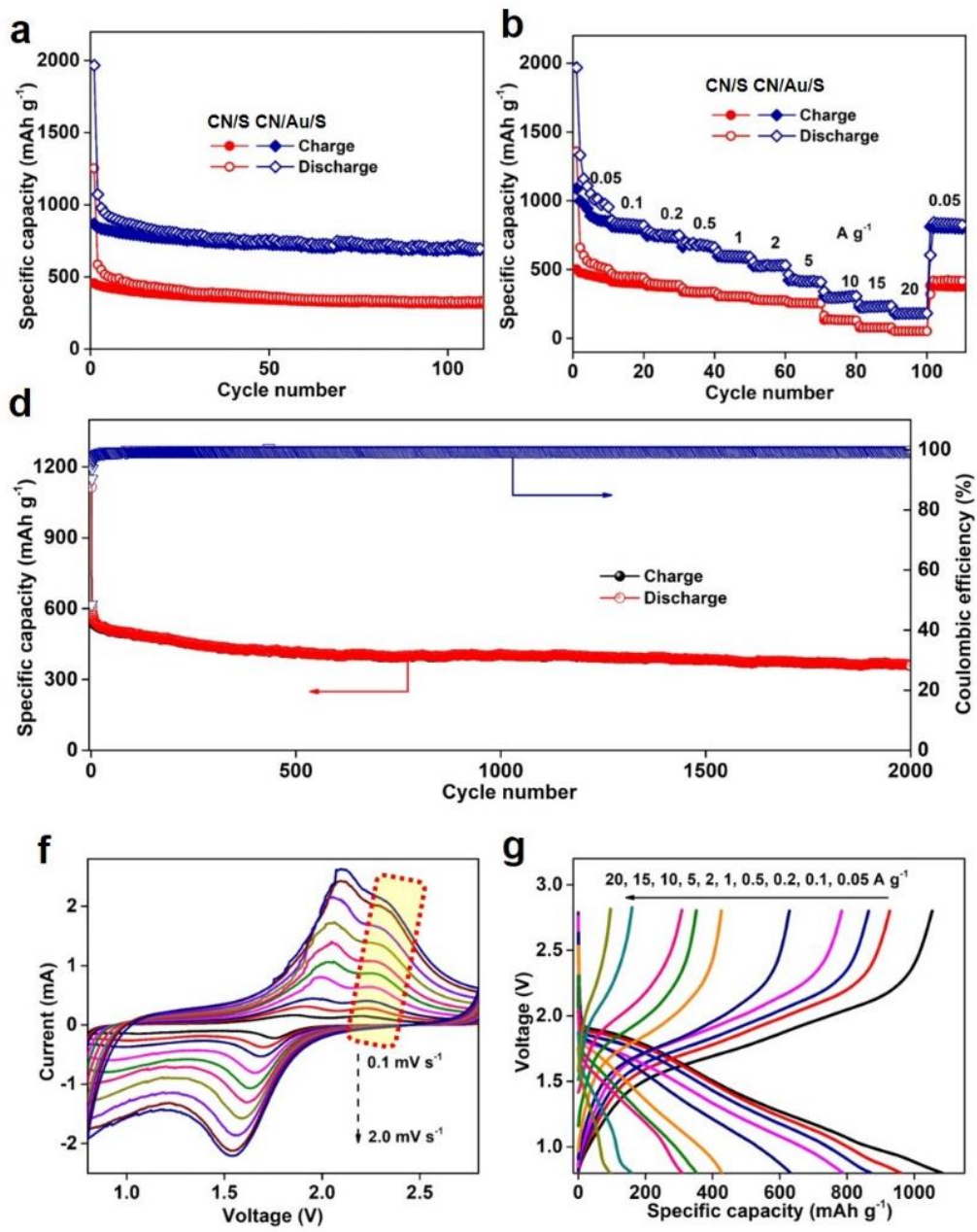
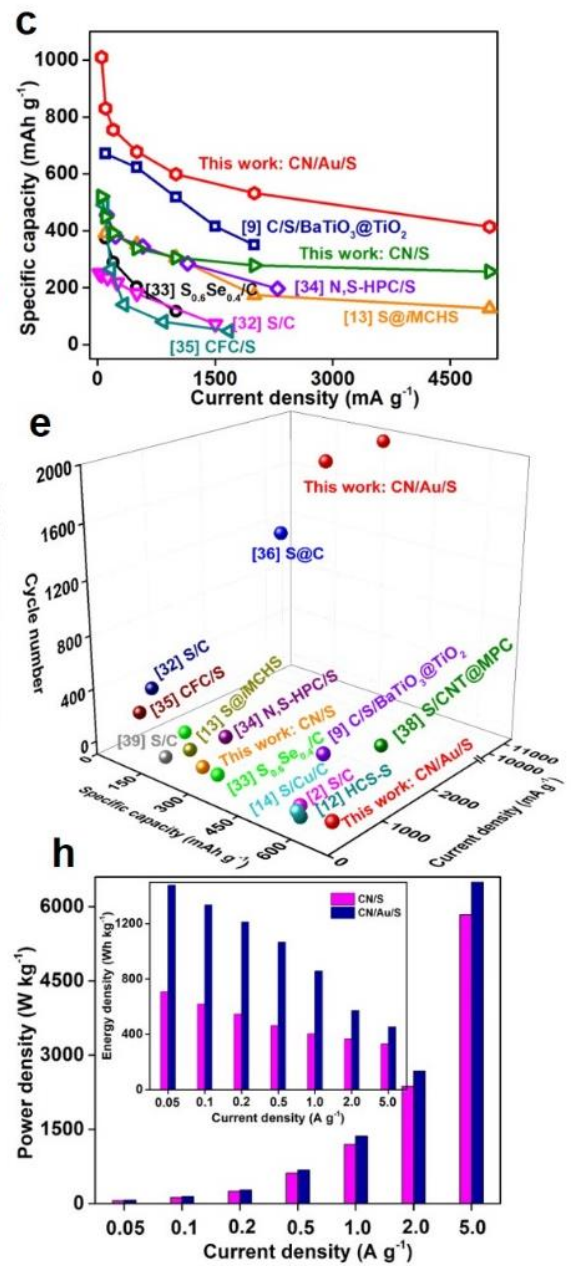

Fig. 5. Electrochemical performance of RT-Na-S batteries. (a) Cycling performance at $0.1 \mathrm{~A} \mathrm{~g}^{-1}$ and (b) rate performance of $\mathrm{CN} / \mathrm{S}$ and $\mathrm{CN} / \mathrm{Au} / \mathrm{S}$ samples. (c) Rate performances of $\mathrm{CN} / \mathrm{S}$ and $\mathrm{CN} / \mathrm{Au} / \mathrm{S}$ samples compared to references. (d) Long-term cycling stability of $\mathrm{CN} / \mathrm{Au} / \mathrm{S}$ sample at a current density of $10 \mathrm{~A} \mathrm{~g}^{-1}$. (e) Cycling performances of $\mathrm{CN} / \mathrm{S}$ and $\mathrm{CN} / \mathrm{Au} / \mathrm{S}$ samples compared to references. (f) $\mathrm{CV}$ curves of $\mathrm{CN} / \mathrm{Au} / \mathrm{S}$ samples from 0.1 to $2.0 \mathrm{mV} \mathrm{s} \mathrm{s}^{-1}$. (g) Charge-discharge curves at various current densities for the $\mathrm{CN} / \mathrm{Au} / \mathrm{S}$ sample. (h) Energy density (inset) and power density of $\mathrm{CN} / \mathrm{S}$ and $\mathrm{CN} / \mathrm{Au} / \mathrm{S}$ samples.

It is indispensable but difficult to realize long-term cycling performance at high rate for current RT-Na-S batteries because of the poor sulfur reaction activity and severe polysulfide shuttle effect. Therefore, prolonged cycling of $\mathrm{CN} / \mathrm{Au} / \mathrm{S}$ was performed at the high rates of $2 \mathrm{~A} \mathrm{~g}^{-1}$ and $10 \mathrm{~A} \mathrm{~g}^{-1}$ (Fig. $5 \mathrm{~d}$ and Fig. S14) to evaluate its longterm cycling stability. Impressively, the $\mathrm{CN} / \mathrm{Au} / \mathrm{S}$ can maintain a reversible capacity of $430 \mathrm{mAh} \mathrm{g}^{-1}$ after 1000 cycles at $2 \mathrm{~A} \mathrm{~g}^{-1}$, and $369 \mathrm{mAh} \mathrm{g}^{-1}$ at $10 \mathrm{~A} \mathrm{~g}^{-1}$ after 2000 cycles. This is the longest cycling lifespan among the present RT-Na-S batteries. Comparing the cycling performance to previous RT Na-S references, the $\mathrm{CN} / \mathrm{Au} / \mathrm{S}$ sample shows remarkable high capacity and stable cycling performance (Fig. $5 e)^{2,9,12-14,32,33-39}$. The enhanced performance of $\mathrm{CN} / \mathrm{Au} / \mathrm{S}$ is attributed to the unique material design strategy. The interconnected $\mathrm{N}$-doped carbon nanosheets could serve as a highly conductive network for sulfur, electrons, and polysulfides.
Moreover, the outer carbon shell could confine the polysulfides, and the $\mathrm{N}$-doping also effectively enhances the interaction between the carbon host and the polysulfides to limit the shuttle effect. Most importantly, the $\mathrm{Au}$ nanodots can catalyze polysulfide transformation, which improves the sulfur reactivity and utilization. Thus, the $\mathrm{CN} / \mathrm{Au} / \mathrm{S}$ is a very effective sulfur host for RT-Na-S batteries.

To further understand the $\mathrm{Au}$ catalytic effect and the outstanding electrochemical performance of $\mathrm{CN} / \mathrm{Au} / \mathrm{S}$, the electrochemical impedance spectroscopy (EIS) and CV curves at various rates were collected. As shown in Fig. S15, CN/Au/S presents lower charge transfer resistance than $\mathrm{CN} / \mathrm{S}$, which may arise from the improved conductivity of $\mathrm{Au}$ nanodots. In addition, the charge transfer resistance gradually decreases during cycling, which demonstrates the dynamic activation process of the electrodes, enabling long cycling performance. This is different from the previous 
reported RT-Na-S batteries, which exhibited an impedance increase owing to the accumulation of $\mathrm{Na}_{2} \mathrm{~S}$ in the cathode during cycling, causing a gradual capacity loss. It is worth pointing out that the cathodic peak around $2.4 \mathrm{~V}$ in $\mathrm{CN} / \mathrm{Au} / \mathrm{S}$ attributed to the transformation of $\mathrm{Na}_{2} \mathrm{~S}_{4}$ to $\mathrm{S}$ can be observed in the CV curves at every rate (Fig. $5 f$ ), demonstrating that $\mathrm{Au}$ nanodots can catalyze polysulfide transformation even at high current density. In comparison, without the Au nanoparticles, the peak gradually disappears with increasing scan rate (see Fig. S16). In addition, the peak at $1.04 \mathrm{~V}$ (ascribed to the conversion of $\mathrm{Na}_{2} \mathrm{~S}_{4}$ to $\mathrm{NaS}_{2}$ ) of $\mathrm{CN} / \mathrm{Au} / \mathrm{S}$ is also stronger than that of $\mathrm{CN} / \mathrm{S}$, which means that the $\mathrm{Au}$ nanoparticles are still working in the cathodic process. This process is further confirmed by the fact that the $\mathrm{CN} / \mathrm{Au} / \mathrm{S}$ sample presents smaller polarization than the $\mathrm{CN} / \mathrm{S}$ at higher current densities (Fig. $5 \mathrm{~g}$ and Fig. S17). It should be noted that the gravimetric energy/power densities are affected by the specific capacity, and thus the CN/Au/S sample delivers higher gravimetric energy/power densities than $\mathrm{CN} / \mathrm{S}$ (Fig. 5h). Therefore, the $\mathrm{CN} / \mathrm{Au} / \mathrm{S}$ cathode is a reasonable choice for RT-Na-S batteries.

\section{Conclusions}

In summary, we describe an emerging high-performance RT-Na$\mathrm{S}$ battery in which $\mathrm{N}$-doped carbon microspheres decorated with gold nanodots serve as an effective sulfur host. The crosslinking inside channels permits mass transport and electrolyte infiltration. The nitrogen doping and gold nanodots can enhance the adsorption between the polysulfides and carbon via polar-polar interactions. Furthermore, the thick outside shell can physically confine the reactions inside of the sphere, which can relieve the polysulfide shuttle effect. More importantly, the gold nanodots play a very critical role as an electrocatalyst, which enables the intermediate $\mathrm{Na}_{2} \mathrm{~S}_{4}$ to be completely transformed into the final product $\mathrm{Na}_{2} \mathrm{~S}$, contributing to enhanced reactivity of the sulfur cathode and high accessible capacity. Thus, the resultant $\mathrm{CN} / \mathrm{Au} / \mathrm{S}$ cathode presents long cycling stability and high rate capacity $\left(701 \mathrm{mAh} \mathrm{g}^{-1}\right.$ after 110 cycles at a $0.1 \mathrm{~A} \mathrm{~g}^{-1}$ and $369 \mathrm{mAh} \mathrm{g}^{-1}$ after 2000 cycles at $10 \mathrm{~A} \mathrm{~g}$ $\left.{ }^{1}\right)$. This work not only provides a deeper understanding of catalyzing the activity of sulfur molecules in RT-Na-S batteries, but also opens new opportunities to enable high-performance RT-Na-S batteries for grid-scale stationary energy storage systems.

\section{Author Contributions}

G.Y and S.D. supervised the project. N.W., Y.W and Z.B designed and performed the experiments. Z.X. designed and performed the DFT calculations. Y.W. help with the in-situ synchrotron XRD. Z.F., X.Z., $X . X$. and Y.D. helped with the experiment and discussion section. N.W. and Z.B. wrote the manuscript. Y.W., S.D. and G.Y revised the manuscript. All authors were involved in the discussion of data analysis and commented on the manuscript. N.W., Y.W and Z.B have contributed equally to this work.

\section{Conflicts of interest}

There are no conflicts to declare.

\section{Acknowledgements}

G. Y. acknowledges the funding support from US Department of Energy, Office of Science, Basic Energy Sciences, under Award DE-SC0019019. S.D. acknowledges the financial support from the Australian Research Council (ARC) through Discovery Projects (DP160102627), a Linkage Project (LP160100273), and Discovery Early Career Researcher Award (DE170100928). The authors thank Dr. Tania Silver, Ningyan Cheng and Dr. Li Wang for helpful discussions.

\section{Notes and references}

1 M. Armand, J.-M. Tarascon, Nature, 2008, 451, 652.

2 S. Wei, S. Xu, A. Agrawral, S. Choudhury, Y. Lu, Z. Tu, L. Ma, L. A. Archer, Nat. Commun., 2016, 7, 11722.

3 Y.-X. Wang, B. Zhang, W. Lai, Y. Xu, S.-L. Chou, H.-K. Liu, S.-X. Dou, Adv. Energy Mater., 2017, 7, 1602829.

4 A. Manthiram, X. Yu, Small, 2015, 11, 2108.

5 I. Bauer, M. Kohl, H. Althues, S. Kaskel, Chem. Commun., 2014, 50, 3208.

6 S. Wei, L. Ma, K. E. Hendrickson, Z. Tu, L. A. Archer, J. Am. Chem. Soc., 2015, 137, 12143.

7 H. Ye, L. Ma, Y. Zhou, N. Han, F. Zhao, J. Deng, T. Wu, Y. Li, J. Lu, Proc. Natl. Acad. Sci. U.S.A., 2017, 114, 13091.

8 Z. Li, J. Zhang, Y. Lu, X. W. Lou, Sci. Adv., 2018, 4, 1687.

9 D. Ma, Y. Li, J. Yang, H. Mi, S. Luo, L. Deng, C. Yan, M. Rauf. P. Zhang, X. Sun, X. Ren, J. Li, H. Zhang, Adv. Funct. Mater., 2018, 28, 1705537.

10 C.-W. Park, H.-S. Ryu, K.-W. Kim, J.-H. Ahn, J.-Y. Lee, H.-J. Ahn, J. Power Sources, 2007, 165, 450.

11 S. Xin, L. Gu, N.-H. Zhao, Y.-X. Yin, L.-J. Zhou, Y.-G. Guo, L.-J. Wan, J. Am. Chem. Soc., 2012, 134, 18510.

12 D.-J. Lee, J.-W. Park, I. Hasa, Y.-K. Sun, B. Scrosati, J. Hassoun, J. Mater. Chem. A, 2013, 1, 5256.

13 Y.-X. Wang, J. Yang, W. Lai, S.-L. Chou, Q. Gu, H. K. Liu, D. Zhao, S. X. Dou, J. Am. Chem. Soc., 2016, 138, 16576.

14 S. Zheng, P. Han, Z. Han, P. Li, H. Zhang, J. Yang, Adv. Energy Mater., 2014, 4, 1400226.

15 B. W. Zhang, T. Sheng, Y-X. Wang, S. L. Chou, K. Davey, S-X. Dou, S-Z. Qiao, Angew. Chem., 2019, 131, 1498.

16 B. W. Zhang, T. Sheng, Y-D. Liu, Y-X. Wang, L. Zhang, W-H. Lai, L. Wang, J. P. Yang, Q-F. Gu, S-L. Chou, H-K. Liu, S-X. Dou, Nat. Commun., 2018, 9, 4082.

17 H. A. Salem, G. Babu, C. V. Rao, L M. R. Arava, J. Am. Chem. Soc., 2015, 137, 11542.

18 Z. Du, X. Chen, W. Hu, C. Chuang, S. Xie, A. Hu, W. Yan, X. Kong, X. Wu, H. Ji, L.-J. Wan, J. Am. Chem. Soc., 141, 3977.

19 X. Liang, C. Hart, Q. Pang, A. Garsuch, T. Weiss, L. F. Nazar, Nat. Commun., 2015, 6, 5682.

20 Z.-L. Xu, S. Lin, N. Onofrio, L. Zhou, F. Shi, W. Lu, K. Kang, Q. Zhang, S. P. Lau, Nature Commun., 2018, 9, 4164.

21 G. Babu, N. Masurkar, H. Al Salem, L. M. Arava, L. M. R, J. Am. Chem. Soc., 2017, 139, 171.

22 Z. Sun, J. Zhang, L. Yin, G. Hu, R. Fang, H.-M. Cheng, F. Li, Nat. Commun., 2017, 8, 14627.

23 T.-G. Jeong, D. S. Choi, H. Song, J. Choi, S.-A. Park, S. H. Oh, H. Kim, Y. Jung, Y.-T. Kim, ACS Energy Lett., 2017, 2, 327.

24 M. S. Inkpen, Z.-F. Liu, H. Li, L. M. Campos, J. B. Neaton, L. Venkataraman, Nat. Chem., 2019, 11, 351.

25 T. Fujita, P. Guan, K. McKenna, X. Lang, A. Hirata, L. Zhang, T. Tokunaga, S. Arai, Y. Yamamoto, N. Tanaka, Y. Ishikawa, N. 
Asao, Y. Yamamoto, J. Erlebacher, M. Chen, Nat. Mater., 2012, 11, 775.

26 X. Lang, A. Hirata, T. Fujita, M. Chen, Nat. Nanotech., 2011, 6, 232.

27 B. Zhang, X. Qin, G. R. Li, X. P. Gao, Energy Environ. Sci., 2010, 3, 1531.

28 Q. Pang, J. Tang, H. Huang, X. Liang, C. Hart, K. C. Tam, L. F. Nazar, Adv. Mater., 27, 6021.

29 A. T. E. Vilian, V. Veeramani, S.-M. Chen, R. Madhu, C. H. Kwak, Y. S. Huh, Y.-K. Han, Sci. Rep., 2015, 5, 18390.

30 N. Wang, Z. Xu, X. Xu, T. Liao, B. Tang, Z. Bai, S. Dou, ACS Appl. Mater. Interfaces, 2018, 10, 13573.

31 T.-Z. Hou, X. Chen, H.-J. Peng, J.-Q. Huang, B.-Q. Li, Q. Zhang, B. Li, Small, 2016, 12, 3283.

32 T. H. Hwang, D. S. Jung, J.-S. Kim, B. G. Kim, J. W. Choi, Nano Lett.2013, 13, 4532.

33 Y. Yao, L. Zeng, S. Hu, Y. Jiang, B. Yuan, Y. Yu, Small, 2017, 13, 1603513.

34 Z. Qiang, Y.-M. Chen, Y. Xia, W. Liang, Y. Zhu, B. D. Vogt, Nano Energy, 2017, 32, 59.

35 Q. Lu, X. Wang, J. Cao, C. Chen, K. Chen, Z. Zhao, Z. Niu, J. Chen, Energy Storage Materials, 2017, 8, 77.

36 R. Carter, L. Oakes, A. Douglas, N. Muralidharan, A. P. Cohn, C. L. Pint, Nano Lett., 2017, 17, 1863.

37 X. Yu, A. Manthiram, J. Phys. Chem. C, 2014, 118, 22952

38 S. Xin, Y.-X. Yin, Y.-G. Guo, L.-J. Wan, Adv. Mater., 2014, 26, 1261.

39 S. Wenzel, H. Metelmann, C. Raiß, A. K. Dürr, J. Janek, P, J. Power Sources, 2014, 243, 758. 


\section{Table of contents}

Developing novel gold nanoclusters as an electrocatalyst can facilitate a completely reversible reaction between $\mathrm{S}$ and $\mathrm{Na}$, achieving advanced high-energy-density room-temperature sodium-sulfur batteries.

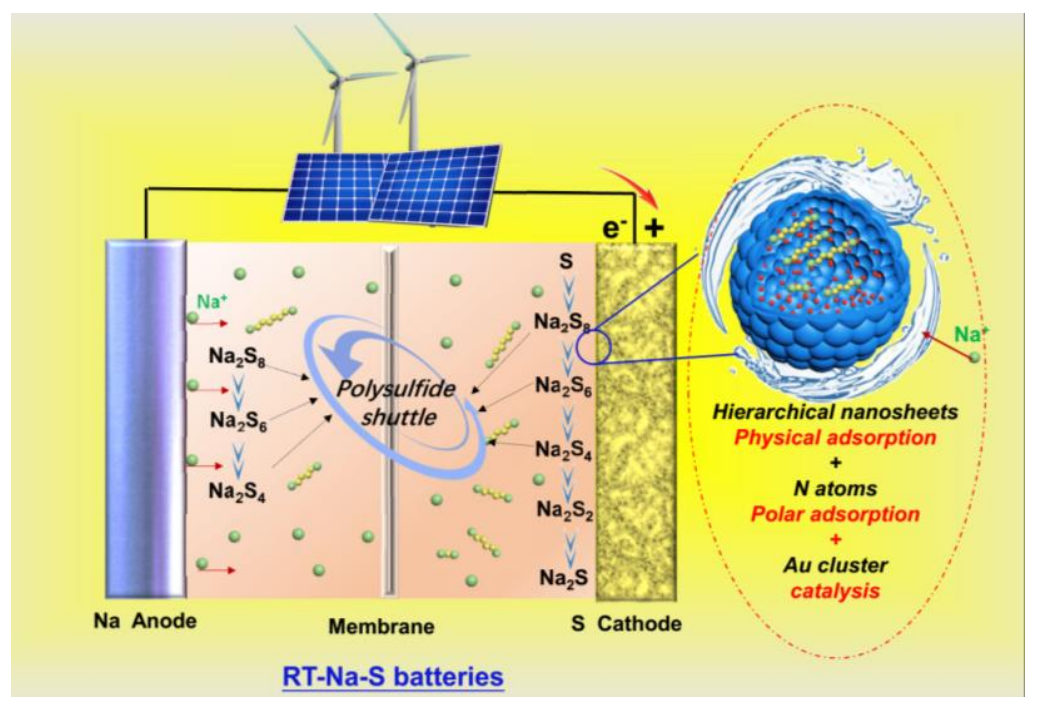

